\title{
Determination of Rosmarinic Acid and Caffeic Acid in Thymus daenensis and Thymus lancifolius Extracts by High-Performance Thin Layer Chromatography
}

\author{
Karami Forough $^{1,2} \mathbb{D}$, Jaberi Samira ${ }^{3}$, Moein Mahmoodreza ${ }^{3,4, *} \mathbb{D}$, Jafari Azizolah ${ }^{5}$ \\ 1 Central Research Laboratory, School of Medicine, Shiraz University of Medical Sciences, Shiraz, Iran; \\ lab_center@sums.ac.ir (K.F.); \\ 2 Department of Chemistry, Yasouj University, Yasouj, Iran; lab_center@sums.ac.ir (K.F.); \\ 3 Medicinal Plants Processing Research Center, Shiraz University of Medical Sciences, Shiraz, Iran; \\ S_Jaberi2012@yahoo.com (J.S.); mrmoein@sums.ac.ir (M.M.); \\ 4 Department of Pharmacognosy, School of Pharmacy, Shiraz University of Medical Sciences, Shiraz, Iran; \\ mrmoein@sums.ac.ir (M.M.); \\ 5 Department of Biology, Yasouj University, Yasouj, Iran \\ * Correspondence: mrmoein@sums.ac.ir (M.M.);
}

\begin{abstract}
Thymus species belong to the Lamiaceae family, of which 18 species in the flora of Iran, 6 are endemic to Iran. In the current research, high-performance thin-layer chromatography (HPTLC) technique as an easy, fast, reproducible, and low-cost method was used for the determination of rosmarinic acid and caffeic acid in Thymus lancifolius (T. lancifolius) and two species of Thymus daenensis (T. daenensis) from Iran. Toluene-ethyl acetate-formic acid with a ratio of 67.72-22.90 and $9.38 \%$ was selected as the mobile phase of rosmarinic acid, and ethyl acetate-methanol-formic acidwater with a ratio of 85-8-2 and 5\% was designated as the mobile phase of caffeic acid. The highest and lowest amount of rosmarinic acid was observed for T. daenensis $1(10.54 \pm 0.12 \mathrm{mg} / \mathrm{g})$ and T. lancifolius $(0.46 \pm 0.01 \mathrm{mg} / \mathrm{g})$, respectively. The amount of rosmarinic acid for $T$. daenensis 2 was obtained as $7.85 \pm 0.02 \mathrm{mg} / \mathrm{g}$ for each of the dried plants. In the following, HPTLC analysis of caffeic acid for $T$. daenensis $1, T$. daenensis 2 , and T. lancifolius was acquired amounts of $0.78 \pm 0.007,0.13 \pm 0.007$, and $0.26 \pm 0.007 \mathrm{mg} / \mathrm{g}$ for each of dried plants, respectively. Therefore, regarding the special effects of phenolic acids and properties of the Thymus genus, the acquired results are suitable for application in pathogenic research, infections, immunology diseases, and evaluation of the antioxidant activity.
\end{abstract}

Keywords: caffeic acid; high-performance thin-layer chromatography; rosmarinic acid; Thymus daenensis; Thymus lancifolius.

(C) 2021 by the authors. This article is an open-access article distributed under the terms and conditions of the Creative Commons Attribution (CC BY) license (https://creativecommons.org/licenses/by/4.0/).

\section{Introduction}

The genus Thymus, recognized as "Avishan" in Persian, belongs to the Lamiaceae family, of which 18 species in the flora of Iran, 6 are endemic to Iran [1,2]. Antiseptic, antitussive, antibacterial, antifungal, antivirus, expectorant, and antispasmodic properties of Thymus species have been reported [3-5]. The aerial parts of Thymus species have been suggested in traditional medicine as carminative, digestive, antispasmodic, antitussive, and expectorant [6]. The most medicinal properties of Thymus species are related to their essential oils, particularly thymol [1, 7], phenolic acids, flavonoids, and tannins [8]. As a species of the 
Thymus genus, Thymus daenensis (T. daenensis) is used for its aromatic properties and medicinal effects [9]. T. daenensis, known as "Avishane-denaei" in Persian, grows wildly in the central and northwestern parts of Iran [10]. Various species of the Lamiaceae family are very rich in flavonoids, phenolic acids, and phenolic diterpenes, which show great antioxidant effects, impediment or restrain the activity of free radicals [11-15]. Rosmarinic acid (RA) as an ester of caffeic acid (CA) and 3,4-dihydroxy phenyl lactic acid acts like a defense compound against cancer [16]. RA's attendance in medicinal plants, herbs, and spices has valuable and health-stimulating effects [16]. Adstringent, antioxidative, anti-inflammatory, antimutagen, antibacterial, and antiviral activities have been described for RA as a phenolic compound [17]. Caffeic acid (CA) as another phenolic acid significantly influences plants' protein solubility [18]. CA is generally recognized for hepatoprotective and hypolipidaemic activities via inhibition of lipid peroxidation and antioxidant properties.

For the analysis of complex mixtures, high-performance thin-layer chromatography (HPTLC) has several benefits over other analytical techniques: simultaneous determination of various samples, small amounts of the mobile phase, automation, easy sample preparation, rapid analysis, and inexpensive [19].

Despite many studies on the medicinal or functional properties of the Thymus genus, only a few reports have been described to measure the phenolic constituents of these plants. The current research aims to determine RA and CA in the Thymus genus using HPTLC as a fast, reproducible, and cheap technique.

\section{Materials and Methods}

\subsection{Chemicals.}

HPTLC plate silica gel 60 F $_{254}(20 \times 10$ cm, Merck, Darmstadt, Germany); MeOH; toluene; ethyl acetate (Samchun, Korea); formic acid purity of 99.9\% (Biochem, France); rosmarinic acid and caffeic acid (Sigma-Aldrich, Germany) were purchased. All materials were of analytical grade.

\subsection{Sample preparation.}

The aerial parts of T. lancifolius, T. daenensis 1, and T. daenensis 2 were collected from Moorgol Peak (Kohgiluyeh and Boyer-Ahmad Province, Iran), Sheshpeer (Fars Province, Iran), and Kakan (Kohgiluyeh and Boyer-Ahmad Province, Iran) in July 2013, respectively. Voucher herbarium specimens of the Thymus genus were described in Table 1 . The plants were dried at a temperature of $28^{\circ} \mathrm{C}$ and then powdered. The extraction procedure was performed using two methods of reflux and ultrasonic. For the reflux procedure, $2 \mathrm{~g}$ of each powdered plant was dissolved in $50 \mathrm{~mL}$ of $\mathrm{MeOH}$ and heated under reflux for $30 \mathrm{~min}$, four times. The methanolic extracts were combined, concentrated, and diluted using distilled water with a ratio of 1:1. In the following, each solution was extracted four times with $100 \mathrm{~mL}$ petroleum ether. The aqueous layers were concentrated to $1 \mathrm{~mL}$ and filled up to $10 \mathrm{~mL}$ with $\mathrm{MeOH}$ to provide a dilution factor $(\alpha)$ of 0.1 . Finally, $2 \mathrm{~mL}$ of the obtained solution was diluted using $\mathrm{MeOH}$ to acquire a solution with $\alpha=0.02$.

For the ultrasonic procedure, $2 \mathrm{~g}$ of each powdered plant was dissolved in $50 \mathrm{~mL}$ of $\mathrm{MeOH}$ and heated under an ultrasonic water bath for $15 \mathrm{~min}$ at a temperature of $80^{\circ} \mathrm{C}$. After filtration, the method was followed like the first method. 
Stock solutions of 0.05 and $0.005 \mathrm{mg} \mathrm{mL}^{-1} \mathrm{RA}$ and CA were prepared using dissolving appropriate amounts of RA and $\mathrm{CA}$ in $\mathrm{MeOH}$.

Table 1. Ecological distribution of Thymus species.

\begin{tabular}{l|l|l} 
Plants Name & Herbarium No. & Collection Data \\
\hline T. lancifolius & HYU 30231 & Faculty of Agriculture, Yasouj University, Iran. \\
\hline T. daenensis 2 & HYU 30245 & Faculty of Agriculture, Yasouj University, Iran. \\
\hline T. daenensis 1 & 568 & $\begin{array}{l}\text { Department of Pharmacognosy, Shiraz University of Medical } \\
\text { Sciences, Shiraz, Iran. }\end{array}$
\end{tabular}

\subsection{Instrumental parameters}

Chromatographic separation at room temperature and $20 \%$ humidity was performed by Camag HPTLC, made in Switzerland, equipped with ATS4, ADC2, scanner 3, and visualizer. The samples, in the form of a band, were spotted by ATS4 under $\mathrm{N}_{2}$ gas ( 5 bar pressure) on an HPTLC plate silica gel $60 \mathrm{~F}_{254}(20 \times 10 \mathrm{~cm})$ with a band length of $6 \mathrm{~mm}$ and distance of between tracks $11.3 \mathrm{~mm}$. $15 \mu \mathrm{l}$ of extracts solution of T. lancifolius, T. daenensis 1 , and $T$. daenensis 2 was applied. Developing of the plates was done by ADC2 to the following parameters: toluene-ethyl acetate-formic acid with a ratio of $67.72-22.90$ and $9.38 \%$, respectively as the mobile phase of RA and ethyl acetate-methanol-formic acid-water with a ratio of 85-8-2 and 5\%, respectively as the mobile phase of CA; plate preconditioning time 1.0 min; filling volume $10 \mathrm{~mL}$; migration distance $75 \mathrm{~mm}$; and drying time $1.0 \mathrm{~min}$. Scanning of plates at the wavelength of $366 \mathrm{~nm}$ and absorption mode was carried out by scanner 3 to the following settings; slit dimension, $6.00 \mathrm{~mm} \times 0.40 \mathrm{~mm}$, macro; scanning speed, $20 \mathrm{~mm} / \mathrm{s}$; data resolution, $100 \mu \mathrm{m} / \mathrm{step}$; and lamp D2. Finally, the image of plates was obtained by visualizer at 254,366 , and visible wavelengths. Recording of data was done by WinCATS software.

\section{Results and Discussion}

There are different reports about the analysis of essential oil of the Thymus genus, its antioxidant and antifungal activities. For example, analysis of essential oil of $T$. daenensis subspecies daenensis Celak by Alizadeh et al. showed the main components of thymol (66.62$71.49 \%), p$-cymene (5.52-7.12\%), $\beta$-caryophyllene (3.91-4.09\%), $\delta$-terpinene $(3.22-4.3 \%)$ and carvacrol (2.64-2.77\%) [10]. Also, total phenolic content, antioxidant and antifungal activity of $T$. daenensis were investigated by Alizadeh et al. [10]. A similar analysis by Amiri showed high antioxidant activity of polar subfraction of $T$. daenensis subspecies lancifolius (Celak) Jalas in DPPH assay [2].

The chemical composition of essential oil of investigated plants in the current research was studied by Jaberi et al. [20]. Thymol (39.91\%), carvacrol (29.93\%), linalool (5.55 \%), caryophyllene $(3.5 \%)$ and geraniol $(3.09 \%)$ were identified as the major components of the essential oil of $T$. daenensis, but the major components of the essential oil of T. lancifolius were as follows: carvacrol $(25.55 \%)$, thymol $(20.79 \%)$, linalool $(16.8 \%)$, $\alpha$-terpineol $(6.34 \%)$, borneol $(4.00 \%)$, caryophyllene (3.98\%), p-cymene $(3.38 \%)$ and cis-linalool oxide $(3.21 \%)$. Furthermore, essential oil composition and antioxidant activity of ethanolic extract of $T$. daenensis Celak was studied by Sabahi et al. [21]. Their research demonstrated no antioxidant ability by ferric-reducing antioxidant power (Frap) assay, whereas the extract showed antioxidant activity. Other RA and CA measurements in Thymus extracts were performed using LC-MS [22] and HPLC [23-25]. 
In the current study, CA and RA's determination as phenolic compounds in the Thymus genus was investigated. The extraction procedure was done by two methods of reflux and ultrasonic, which caused the same results. So, due to the similarity between data, only the ultrasonic results were reported. Extraction procedures based on ultrasound have shown a great attraction because of their affirmative effects on time and yield of extraction, particle size, and solvent consumption [26, 27]. The best solvent system for chromatographic separation of RA was toluene-ethyl acetate-formic acid with the ratio of 67.72-22.90 and 9.38\%, respectively. Also, ethyl acetate-methanol-formic acid-water with a ratio of 85-8-2 and 5\%, respectively, was selected as the CA's mobile phase. The spots of RA and CA at the wavelength of $366 \mathrm{~nm}$, seen as blue bonds on the HPTLC plate, were detected at an $R_{f}$ value of $0.11 \pm 0.02$ for RA and $0.73 \pm 0.02$ for CA (Figure 1). Subsequently, there was no overlap with each other. In the following, TLC scanner 3 was applied for detection and quantitation of RA and CA at the wavelength of $366 \mathrm{~nm}$. Finally, RA and CA with different $\mathrm{R}_{\mathrm{f}}$ values were visualized as blue bonds under $366 \mathrm{~nm}$.

Standard solutions of 0.05 and $0.005 \mathrm{mg} \mathrm{mL}^{-1} \mathrm{RA}$ and CA in amount per fraction mode was used to obtain calibration curves of RA at concentrations of 4, 6, 8, 10, 12, 14, and 20 $\mathrm{ng} / \mathrm{spot}$ and 2, 4, 6, 10, 14, 18, and $20 \mathrm{ng} / \mathrm{spot}$ for CA by plotting the amounts of standard compounds versus equivalent area of each bond. Statistical parameters and equations were shown in Table 2. The RA quantitation was led to amounts of $0.46 \pm 0.01,10.54 \pm 0.12$, and $7.85 \pm 0.02 \mathrm{mg} / \mathrm{g}$ for $T$. lancifolius, $T$. daenensis 1 , and $T$. daenensis 2 , respectively. Furthermore, the CA determination was caused to values of $0.26 \pm 0.007,0.78 \pm 0.007$, and $0.13 \pm 0.007 \mathrm{mg} / \mathrm{g}$ for $T$. lancifolius, $T$. daenensis 1 , and $T$. daenensis 2 , respectively. It is seen the highest amount of RA, and CA was obtained for T. daenensis 1 . However, the geographical distribution of $T$. daenensis 2 and $T$. lancifolius are the same. The amount of RA for $T$. daenensis 2 was higher than T. lancifolius. and value of CA in T. daenensis 2 was lower than T. lancifolius. Also, the measurement for RA and CA evaluations was validated. Therefore, the calibration curve was assessed via plotting chromatographic peak areas versus standards concentration based on $\mathrm{ng} / \mathrm{spot}$. Limit of detection (LOD) and limit of quantification (LOQ) using the equations of LOD $=3 \times S D / b$ and LOQ $=10 \times S D / b$ were calculated to determine the quantitation sensitivity, which SD displays the standard deviation of peak areas of the standard and $b$ is the slope of the linear equation. As shown in Table 2, LODs of 30.19 and $3.65 \mathrm{ng} / \mathrm{spot}$ were achieved for RA and CA, respectively. Similarly, LOQs of 91.53 and 11.06 $\mathrm{ng} /$ spot were obtained for RA and CA, respectively. High correlation amounts $\left(\mathrm{r}^{2}\right)$ for RA and CA measurements present high correlation of the fitted regression lines.

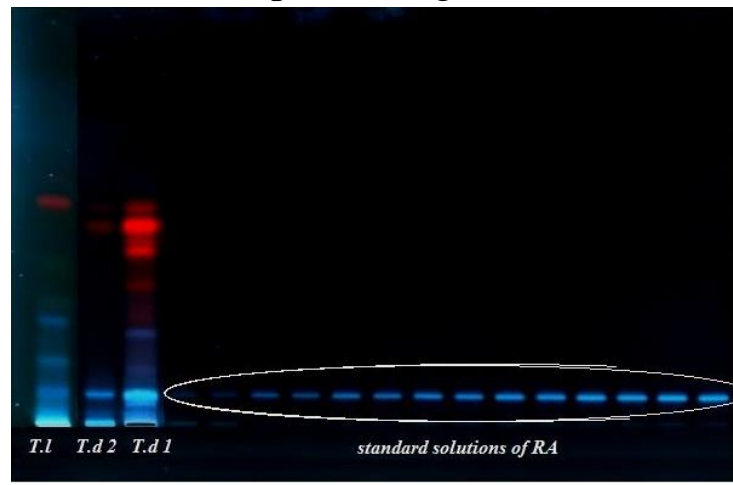

(a)

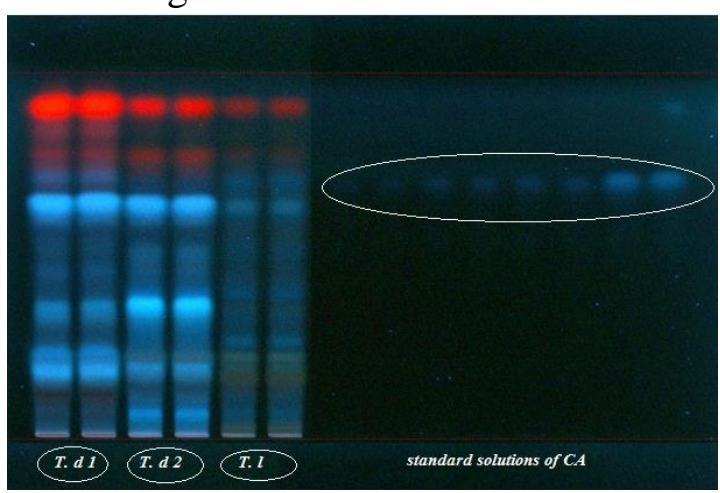

(b)

Figure 1. HPTLC chromatograms of Thymus genera under $366 \mathrm{~nm}$ (T.d 1: T. daenensis 1, T.d 2: T. daenensis 2 , T.1: T. lancifolius, RA: rosmarinic acid, CA: caffeic acid). (a) determination of rosmarinic acid; (b) determination of caffeic acid. 
Table 2. The amounts of rosmarinic acid and caffeic acid in methanolic extracts of different Thymus genera.

\begin{tabular}{l|l|l} 
& Rosmarinic acid & Caffeic acid \\
\hline$R_{\mathrm{f}}$ values & $0.11 \pm 0.02$ & $0.73 \pm 0.02$ \\
\hline Linear equation & $\mathrm{y}=7.18 \mathrm{x}+602.97$ & $\mathrm{y}=9.64 \mathrm{x}-297.03$ \\
\hline $\mathrm{R}^{2}$ & 0.994 & 0.994 \\
\hline Linear range (ng) & $100-700$ & $30-200$ \\
\hline LOD (ng/spot) & 30.19 & 3.65 \\
\hline LOQ (ng/spot) & 91.53 & 11.06
\end{tabular}

\section{Conclusions}

In the current study, two reflux and ultrasound methods were applied as the extraction procedures, which resulted in the same data. Concerning the HPTLC technique's benefits, the developed method can be used in food and drug industries as routine analysis. Compared to published reports about essential oil compositions of various Thymus species, surveys on phenolic compounds' determination are limited. The comparison of achieved results exposed that there are significant variations even within the two plants from the same locations of Iran (T. lancifolius and T. daenensis 2). It seems that the acquired differences in quantitation might have related to numerous differences such as type of the genus, climatic, seasonal, geographical, and geological conditions.

\section{Funding}

This research received no external funding.

\section{Acknowledgments}

The authors of the presented research wish to thank Shiraz University of Medical Sciences, Shiraz, Iran, for the support.

\section{Conflicts of Interest}

The authors declare no conflict of interest.

\section{References}

1. Rechinger, K.H. Flora iranica, Akademische Druch-u, Verlagsanstat, Graz-Austria, 1963.

2. Amiri, H. Essential Oils Composition and Antioxidant Properties of Three Thymus Species. Evid. Based Complement. Alternat. Med. 2012, 2012, 728065, https://doi.org/10.1155/2012/728065.

3. Inouye, S.; Takizawa, T.; Yamaguchi, H. Antibacterial activity of essential oils and their major constituents against respiratory tract pathogens by gaseous contact. J. Antimicrob. Chemother. 2001, 47, 565-573, https://doi.org/10.1093/jac/47.5.565.

4. Ashnagar, A.; Gharib Naseri, N.; Ramazani, M. Characterization of the major chemical compounds found in Thymus vulgaris plant grown wildly in Chahar Mahal and Bakhtiari province of Iran. Int J PharmTech Res 2011, 3, 01-04.

5. Chevallier, A. The encyclopedia of medicinal plants, Dorling Kindersley Limited, London, 1996.

6. Zargari, A. Medicinal plants, Tehran University Press (In Persian), Tehran, Iran, 1990; pp. $28-42$.

7. Pirbaloutl, A.G. Medicinal plants used in Chaharmahal and Bakhtyari districts of Iran. Herba Polonica 2009, 55, 69-77, http://www.iripz.pl.

8. Mahadev, K.D.; Vishnu, H.M.; Kashinath, D.K. HPTLC and LC-ESI-MS characterization of ether insoluble phenolic components from n-butanol fraction (EPC-BF) of defatted flaxseed meal. Int. J. Drug Dev. \& Res 2011, 3, 126-130.

9. Nickavar, B.; Mojab, F.; Dolat-Abadi, R. Analysis of the essential oils of two Thymus species from Iran. Food Chem. 2005, 90, 609-611, https://doi.org/10.1016/j.foodchem.2004.04.020. 
10. Alizadeh, A.; Alizadeh, O.; Amari, G.; Zare, M. Essential Oil Composition, Total Phenolic Content, Antioxidant Activity and Antifungal Properties of Iranian Thymus daenensis subsp. daenensis Celak. as in Influenced by Ontogenetical Variation. Journal of Essential Oil Bearing Plants 2013, 16, 59-70, https://doi.org/10.1080/0972060X.2013.764190.

11. Aaby, K.; Hvattum, E.; Skrede, G. Analysis of Flavonoids and Other Phenolic Compounds Using HighPerformance Liquid Chromatography with Coulometric Array Detection: Relationship to Antioxidant Activity. J. Agric. Food Chem. 2004, 52, 4595-4603, https://doi.org/10.1021/jf0352879.

12. Alizadeh, A.; Khoshkhui, M.; Javidnia, K.; Firuzi, O.; Tafazoli, E.; Khalighi, A. Effects of fertilizer on yield, essential oil composition, total phenolic content and antioxidant activity in Satureja hortensis L.(Lamiaceae) cultivated in Iran. Journal of Medicinal Plants Research 2010, 4, 033-040.

13. Kivilompolo, M.; Hyötyläinen, T. Comprehensive two-dimensional liquid chromatography in analysis of Lamiaceae herbs: Characterisation and quantification of antioxidant phenolic acids. J. Chromatogr. 2007, 1145, 155-164, https://doi.org/10.1016/j.chroma.2007.01.090.

14. López, V.; Akerreta, S.; Casanova, E.; García-Mina, J.M.; Cavero, R.Y.; Calvo, M.I. In Vitro Antioxidant and Anti-rhizopus Activities of Lamiaceae Herbal Extracts. Plant Foods Hum. Nutr. 2007, 62, 151-155, https://doi.org/10.1007/s11130-007-0056-6.

15. Zheng, W.; Wang, S.Y. Antioxidant Activity and Phenolic Compounds in Selected Herbs. J. Agric. Food Chem. 2001, 49, 5165-5170, https://doi.org/10.1021/jf010697n.

16. Petersen, M.; Simmonds, M.S.J. Rosmarinic acid. Phytochemistry 2003, 62, 121-125, https://doi.org/10.1016/S0031-9422(02)00513-7.

17. Parnham, M.J. Rosmarinic acid. Drugs Future 1985, 10, 756-757.

18. Mieth, G.; Pohl, J.; Kozlowska, H.; Rotkiewicz, D.A. Phenolic constituents of sunflower seed II. Effect of phenolic acids on solubility characteristics of plant proteins. Nahrung 1992, 26, K11-K13.

19. Tomczyk, M.; Bazylko, A.; Bonarewicz, J. Method development and validation for optimized separation of quercetin derivatives in selected Potentilla species using high-performance thin-layer chromatography photodensitometry method. J. Pharm. Biomed. Anal. 2012, 61, 265-270, https://doi.org/10.1016/j.jpba.2011.12.010.

20. Jaberi, S.; Moein, M.; Azizolah, J.; Karami, F. Chemical compositions of two endemic Thymus species essential oil. Trends in Pharmaceutical Sciences 2015, 1, 83-86.

21. Sabahi, Z.; Zarshenas, M.M.; Farmani, F.; Faridi, P.; Moein, S.; Moein, M. Essential oil composition and in vitro antioxidant activity of ethanolic extract of Thymus daenensis Celak from Iran. Global Journal of Pharmacology 2013, http://eprints.hums.ac.ir/id/eprint/965.

22. Boros, B.; Jakabová, S.; Dörnyei, Á.; Horváth, G.; Pluhár, Z.; Kilár, F.; Felinger, A. Determination of polyphenolic compounds by liquid chromatography-mass spectrometry in Thymus species. J. Chromatogr. 2010, 1217, 7972-7980, https://doi.org/10.1016/j.chroma.2010.07.042.

23. Wang, H.; Provan, G.J.; Helliwell, K. Determination of rosmarinic acid and caffeic acid in aromatic herbs by HPLC. Food Chem. 2004, 87, 307-311, https://doi.org/10.1016/j.foodchem.2003.12.029.

24. Raudone, L.; Zymone, K.; Raudonis, R.; Vainoriene, R.; Motiekaityte, V.; Janulis, V. Phenological changes in triterpenic and phenolic composition of Thymus L. species. Industrial Crops and Products 2017, 109, 445451, https://doi.org/10.1016/j.indcrop.2017.08.054.

25. Shekarchi, M.; Hajimehdipoor, H.; Saeidnia, S.; Gohari, A.R.; Hamedani, M.P. Comparative study of rosmarinic acid content in some plants of Labiatae family. Pharmacogn. Mag. 2012, 8, 37, https://doi.org/10.4103/0973-1296.93316.

26. Kadam, S.U.; Donnell, C.P.; Rai, D.K.; Hossain, M.B.; Burgess, C.M.; Walsh, D.; Tiwari, B.K. Laminarin from Irish Brown Seaweeds Ascophyllum nodosum and Laminaria hyperborea: Ultrasound Assisted Extraction, Characterization and Bioactivity. Mar. Drugs 2015, 13, https://doi.org/10.3390/md13074270.

27. Kadam, S.U.; Tiwari, B.K.; Álvarez, C.; O'Donnell, C.P. Ultrasound applications for the extraction, identification and delivery of food proteins and bioactive peptides. Trends Food Sci. Technol. 2015, 46, 6067, https://doi.org/10.1016/j.tifs.2015.07.012. 